\title{
Erradicación de la pobreza y calidad en la salud: elementos indispensables para alcanzar la cohesión social en Colombia
}

\author{
Gloria Mercedes Cortés Saavedra ${ }^{1}$, Silvia E Campuzano $\mathrm{F}^{1}$, Andrea Marcela Turriago $\mathrm{C}^{1}$ \\ 1. Grupo BAZERI. Universidad Colegio Mayor de Cundinamarca. \\ Universidad Santo Tomás. \\ Correspondencia: scampuzano@unicolmayor.edu.co
}

Recibido: 02/03/2013 Aceptado: 20/07/2013

\begin{abstract}
Resumen
Colombia ha sido recientemente definida como uno de los países con mayor inequidad, marcada con desigualdades y brechas socioeconómicas muy amplias, situación que exige que urgentemente se busquen herramientas de cohesión social, que permitan mejorar la calidad de vida de la población, y que a la vez, permitan enfrentar los retos de la globalización, mediante la integración a un mundo que cada vez es más heterogéneo. En este contexto, la cohesión social es relevante y se determina como el diálogo constante entre la exclusión y la inclusión social, determinada por características particulares como el empleo, el bienestar y la salud, entre otros aspectos, que dan cuenta de una adecuada calidad de vida para los individuos, de forma que se sienta una pertenencia a la sociedad.
\end{abstract}

Frente a esta necesidad, se requiere que los países se preocupen por hacer valer los principios de equidad, desarrollo social, gobernabilidad y Estado Social de derecho. En consonancia con loa anterior, en este artículo se hace una revisión sistemática sobre la incidencia de la pobreza como factor de riesgo en la calidad de la salud, especialmente referida a la desnutrición, como elementos que deben ser mejorados para empezar a pensar en cohesión social. Surge como antecedentes en el desarrollo del proyecto de investigación "Intervención de la pobreza mediante la aplicación de un modelo de emprendimiento".

Palabras clave: desnutrición, cohesión social, pobreza, salud.

\section{Eradication of poverty and quality in health: essential elements to achieve social cohesion in Colombia}

Colombia has recently been defined as one of the countries with great inequity, marked with inequalities and very extensive socio-economic gaps, a situation that requires to urgently look for tools of social cohesion that allow Colombians to improve the quality of life for the population and, at the same time, to meet the challenges of globalization, through the integration to a world that is becoming increasingly heterogeneous. Within this context, social cohesion is relevant and is determined as the constant dialog between the exclusion and social inclusion, as determined by particular characteristics such as employment, welfare, and health among others that give an account of an adequate quality of life for individuals, so that there is a feeling of belonging to society.

In response to this need, it is required that the countries worry about upholding the principles of equity, social development, governance, and a social state of law. Consequently, this article makes a systematic review of the incidence of poverty as a risk factor in the quality of health care, especially referring to malnutrition, as an item that should be improved to start thinking about social cohesion. It arises from the search for background on the development of the research project "Intervention of poverty through the application of a model of entrepreneurship".

Key Words: health, malnutrition, poverty, social cohesion. 


\section{Introducción}

" $Y$ si el hambre mata veinte veces más que el Sida, ¿por qué hay tantas movilizaciones por el Sida y no por el hambre? Lamentablemente la respuesta es cinica: El Sida no hace distinción de clases, el hambre si"

Frei Betto

Tal y como lo señala el Secretario Ejecutivo de la CEPAL, José Luis Machinea (2006) en "América Latina y el Caribe el concepto de cohesión social surge ante la necesidad de encarar pertinaces problemas que, pese a algunos avances logrados en los últimos años, aún perduran: altos indices de pobreza e indigencia; la extrema desigualdad que nos caracteriza; diversas formas de discriminación y de exclusión social que se remonta a un lejano pasado". Teniendo fundamento esta valoración la presente propuesta, se centra en la caracterización de la desnutrición como indicador de la salud versus su incidencia en el fortalecimiento de la cohesión social de una comunidad.

El problema de la desnutrición se enmarca en el Plan de Desarrollo 2010-2014 y se operativiza en el programa para la Seguridad Alimentaria horizonte 2014-2019. También tiene como base investigaciones relacionadas con la salud, la desnutrición y la cohesión social, los antecedentes, estadísticas de la salud y la subnutrición en la población infantil y adulta; la cual se encuentra categorizada como crónica y aguda o global en la población infantil; malnutrición y obesidad en la población adulta.

Asimismo, se realiza una revisión del espectro actual de los indicadores cuantitativos y cualitativos tanto de la desnutrición, considerada como un problema de salud pública, como del grado de confluencia entre ésta y la cohesión social. De otra parte, se reportan cifras que confirman la existencia de un total de 800 millones de personas desnutridas a nivel mundial representativas de un $30 \%$, y en
Colombia un $20 \%$ de la población, presenta esta situación; también se asumen algunos de los indicadores cuantitativos de la cohesión social, como: pobreza, ingreso, salud, educación; así como los cualitativos: participación, inclusión social, ciudadanía y sentido de pertenencia, entre otros.

Igualmente, se analiza el concepto de cohesión social, desde las diferentes posturas y perspectivas desde la sociología funcional de E. Durkheim, pasando por reconocidos sociólogos como Bourdieu, Foucault, representantes de la escuela francesa, y otros, hasta la actual declaración de la Unión Europea, respecto a la necesidad de plantear la cohesión como asunto de política pública en el conjunto de naciones que forman parte de esta comunidad internacional.

El artículo es producto de la investigación documental La Desnutrición como indicador de salud en la efectividad de la cohesión social, la cual responde a la línea de investigación, pobreza y exclusión social de la Maestría en Ciencias Económicas-USTA y a la línea de Salud Pública del Grupo BAZERI de la Universidad Colegio Mayor de Cundinamarca y aporta a la conceptualización de la problemática de la desnutrición, al reconocimiento e identificación de sus indicadores cuantitativos y cualitativos, lo que permite realizar el contraste entre la desnutrición y la cohesión social, con la pretensión académica de contribuir a dar respuestas a las preguntas e hipótesis planteadas por los diferentes teóricos consultados como Esping Anderson, Rawell y Joakim Palma, entre otros.

Los autores referenciados consideran que sólo es posible hablar de cohesión social en un Estado de Bienestar socio político y económico, representado por una sociedad justa, redistributiva, residual y participe de la titularidad del pacto social entre el Estado y la sociedad civil, refrendado éste por el pacto fiscal, con alta incidencia en la participación de los derechos sociales, como acceso al trabajo, a la educación, a la salud, a la representación política, 
involucrando a los grupos más vulnerables, lo que contribuye a reducir las diferencias entre ellos. Finalmente, la afirmación sobre la imposibilidad de hablar de cohesión social en el marco de la coexistencia de altos niveles de hambre-desnutrición se demostró con el apoyo del análisis estadístico comparativo entre las diferentes fuentes consultadas.

\section{Referentes teóricos}

Colombia afronta problemas estructurales crecientes que afectan su desarrollo y son motivo de inestabilidad económica, social y política, entre los que se cuenta la inequidad y una de sus principales manifestaciones, la pobreza. Asociados a estos problemas se presentan fenómenos más puntuales, pero no por ello menos complejos como el desempleo, el hambre, la malnutrición, el desplazamiento forzado, la acción de grupos alzados en armas y el narcotráfico, entre otros. Es por la conjunción de estas condiciones, que es necesario fortalecer, reorientar y formular acciones específicas, mejor enfocadas y sobre todo integrales sostenibles en el tiempo, que contribuyan a la solución del problema en general (1).

\section{Hambre-desnutrición como parte impres- cindible de la cohesión social}

La Organización de Estados Americanos (OEA) y la Organización Panamericana de la Salud (OPS) reconocen que el subgrupo hambre-desnutrición causa un daño irreversible en el fortalecimiento del capital social, por cuanto no permiten cualificar los recursos humanos de los países en desarrollo para enfrentar con mejores perspectivas los desafíos de la competitividad, el crecimiento con equidad y la inserción internacional. La ofensiva contra el hambre debe incorporar un consenso ampliado en torno al irreductible derecho de todos los seres humanos a una alimentación adecuada, incluyendo un pacto de cohesión social que infunda en todos el sentimiento de ciudadanía y pertenencia.

El hambre-desnutrición se constituyen en parte imprescindible de la agenda de la cohesión social conformando un subgrupo que se retroalimenta entre sí, generando círculos viciosos de pobreza y exclusión social a lo largo de la vida de las personas, que se transmiten de una generación a otra. Por su parte, la cohesión social se refiere tanto al nivel de inclusión social que alcanza una sociedad como al impacto que dicha inclusión tiene sobre la percepción y sentimiento de pertenencia a esa sociedad por parte de sus distintos actores.

La erradicación del hambre-desnutrición crónica infantil debe ser la prioridad política, y primera urgencia temporal, en el camino hacia una mayor cohesión social y equidad en América Latina y el Caribe, considerada como la región que enfrenta retos particulares en esta problemática, confirmándose en el 2005 una cifra de 53 millones de personas -de las cuales 9 millones correspondía a niños menores de 5 años- que no tenían acceso a alimento suficiente; cifra que entre 2010 y 2012 bajó a 49 millones de personas- de las cuales siete millones corresponde a niños menores de 5 años, lo cual resulta paradójico, por tratarse de un zona que produce un $30 \%$ más de alimentos de los que se necesitarían para alimentar a todos sus habitantes. En consecuencia, el hambre sólo se explica por la profunda inequidad económica, política y social que atenta contra los derechos fundamentales del ser humano (2).

La Política de Acción Social del Gobierno Nacional plantea como objetivo primordial la superación del hambre y la desnutrición infantil como parte prioritaria en la agenda de la cohesión social. Según un informe de la Unicef y Bienestar Familiar, Colombia se ubica en la posición 37 de una clasificación de 81 países en vía de desarrollo cuyos niños tienen retraso de crecimiento debido a la mala alimentación (3).

El derecho a la alimentación se reconoce explícitamente en el artículo 11 del Pacto Internacional de Derechos Económicos, Sociales y Culturales, firmado el 3 de Enero de 1976 el cual señala que el Estado reconoce el derecho fundamental de toda 
persona a estar protegida contra el hambre y estipula que este es responsable de "adoptar individualmente y mediante cooperación Internacional las medidas (programas concretos) que lleven al cumplimiento de ese derecho de protección contra el hambre (4).

Como se expresa en el PNSAN (2012 - 2019) en el país, durante las anteriores tres décadas, se han venido desarrollando una serie de programas y actividades asistenciales de alimentación y nutrición con un enfoque de subsidios y ayuda humanitaria otorgados a través de diferentes instancias, de manera desarticulada e incluso sectorizada, sin atender la política de Estado existente. Ello, hasta cierto punto ha generado sinergias negativas con relación a las condiciones de Seguridad Alimentaria y Nutricional de la población, lo que ha dificultado la protección de las poblaciones en distintos niveles de riesgo y la reducción de diferentes expresiones de hambre y malnutrición (5).

Por lo anterior y atendiendo a las recomendaciones expuestas en el CONPES social 113, de 31 de marzo de 2008, se requería construir el PNSAN, como una herramienta política de planificación y operación que aporte los elementos necesarios para avanzar hacia la articulación y convergencia de todas las acciones que permitan mejorar las condiciones de seguridad alimentaria y nutricional de la población colombiana, teniendo en cuenta las bases del Plan Nacional de Desarrollo (PND) 2010 -2014 Prosperidad para Todos, donde se contempla, entre otros aspectos, la coordinación y armonización con los programas de gestión del riesgo tendientes a disminuir la vulnerabilidad en la producción agroalimentaria ante eventos climáticos adversos (1).

El documento CONPES Social 113 de marzo de 2008 estableció el PNSAN y determinó como una de las estrategias, la necesidad de construir y ejecutarlo, el cual tendría como horizonte de ejecución el periodo 2012-2019, tiempo en el cual debería articularse programática y presupuestalmente con los diferentes planes de desarrollo de la Nación y de las entidades territoriales. A su vez, se promovería la vinculación activa del sector privado y la sociedad civil en su gestión, de financiación, seguimiento y evaluación (5).

El PNSAN es el conjunto de objetivos, metas, estrategias y acciones propuestos por el Estado Colombiano, en un marco de corresponsabilidad con la sociedad civil, que tienen por objeto: 1) proteger a la población de las contingencias que conllevan a situaciones indeseables y socialmente inadmisibles como el hambre y la alimentación inadecuada; 2) asegurar a la población el acceso a los alimentos en forma oportuna, adecuada y de calidad; y 3) lograr la integración, articulación y coordinación de las diferentes intervenciones intersectoriales e interinstitucionales. Así, garantizar un acuerdo social tripartito entre éste, la Política y el Plan de Seguridad alimentaria, el cual se enmarca en la política social del Estado y, como parte de ésta, conformando la política integral de desarrollo y protección social (5).

En este contexto, los planes y acciones se dirigen a toda la población colombiana, no obstante, hacen énfasis en los territorios y poblaciones con mayor privación y vulnerabilidad, entre las cuales están la población en situación de pobreza extrema, desplazada por la violencia y los afectados por desastres naturales; así como también, la población infantil, las mujeres gestantes, las madres en lactancia y los adultos mayores.

De otra parte, atendiendo lo relacionado con la salud y de manera específica la relación de la calidad de la salud con los estados de nutrición, se revisan los conceptos relacionados con los estados de desnutrición que se tienen en cuenta. 


\section{Desnutrición}

Los indicadores frecuentes para medir la desnutrición infantil son: la desnutrición global, la desnutrición crónica, la desnutrición aguda y la prevalencia del bajo peso al nacer, estos indicadores se describen a continuación.

Desnutrición global: se especifica el peso para la edad, se refleja en la masa corporal en relación con la edad biológica y está influida por la talla y el peso del niño, considerándose un indicador compuesto que refleja ampliamente las condiciones estructurales de seguridad alimentaria y nutricional de una población. Según las estadísticas para Bogotá, se observa la tendencia decreciente de este indicador en niños entre 5 y 9 años.

Desnutrición crónica: describe la talla para la edad, mide la velocidad del crecimiento en un espacio de tiempo y permite determinar si hay retraso y sus características; refleja además un proceso de acumulación por la falta de alimentación adecuada durante los años más críticos del desarrollo del nińo (desde la etapa intrauterina hasta los 3 primeros años).

Desnutrición aguda: peso para la talla o índice de masa corporal (IMC) mide el peso corporal con relación a la talla. Permite determinar el déficit de peso con respecto a la talla definida como desnutrición aguda, enflaquecimiento o delgadez, para el caso de niños y niñas menores de 10 años (2).

Prevalencia de bajo peso al nacer: expresa el porcentaje de nacidos vivos con un peso inferior a 2.500 kilogramos sin tener en cuenta la edad gestacional. Para Bogotá, se reporta un $12.5 \%$ del total de nacidos vivos. Este es un indicador de salud materno-infantil, que evalúa la calidad del control prenatal, siendo una causa de morbi-mortalidad en menores de 1 ańo, y asimismo, es predictor de la calidad de vida de la población.

En los determinantes estructurales de la salud se relacionan las condiciones económicas de pobreza, violencia, desempleo, mortalidad y desplazamiento que enfrenta el país; determinantes intermedios: acceso y calidad de la atención, en relación con limitantes, recursos físicos y humanos. Las siguientes cifras señalan que en el 2013, el 34,1\% de los colombianos viven en la pobreza y otro $10,6 \%$ en la indigencia, cerca de 20 millones de personas no tienen acceso a los productos básicos de la canasta familiar. Si estas cifras se comparan con las entregadas por la última Encuesta Nacional de Situación Nutricional (ENSIN) publicada en el 2010, según la cual el $42 \%$ de los hogares del país padece hambre, quizá los datos permitan llegar de nuevo a la conclusión de que la pobreza y la mala nutrición van de la mano (6).

En relación con la mortalidad general, ésta varía según sexo y grupo de edad: las primeras causas de muerte en la población son las siguientes: enfermedad isquemias del corazón (12.6\%), agresiones (9.8\%) y enfermedades cerebro vasculares (5.3\%); Población Infantil: malformación congénita (menores de 1-4 años) determinantes y análisis cromosómicos (23.6\%), trastornos respiratorios del periodo perinatal (23.3\%); Población (6-14) años, transporte terrestre con un $(12 \%)$; leucemias 8.6\%; Adultos Hombres: el 39\%(15-44) agresiones y accidentes (10:3\%); 45-59 enfermedad isquemia del corazón (7).

La meta para 2020 en Bogotá es reducir la mortalidad materna, partiendo de una muestra base de 599 por 100.000 nacidos vivos (7). Los determinantes estructurales, intermedios y proximales por muerte perinatal por 100.000 nacidos vivos, se constituyen en el objetivo del Programa de Atención Infantil (PAI), dirigido principalmente a la reducción de la neumonía y enfermedad diarreica aguda en menores de 5 años.

En este contexto se hace referencia a las enfermedades recurrentes causantes de la mortalidad infantil por grupo de edad en Bogotá: (menores de 5 años). La neumonía por localidades: Suba, Ciudad Bolívar, Bosa; en Chapinero el riesgo por 
neumonía, en menores de este mismo grupo de edad (menores de 5 años) es 1.3 veces mayor comparativamente con las localidades referenciadas; en Kennedy, Usme, Engativá, se observa una tasa decreciente de 1.0 en 2005 a 0.8 en 2010 (8).

\section{Seguridad alimentaria y nutricional}

Combatir la pobreza extrema y el hambre es el primero de los ocho objetivos del Milenio, lo cual conlleva a un compromiso del estado colombiano refrendado en el actual Plan de desarrollo vigencia 2010-2014. ¿Cómo asumen su compromiso las entidades territoriales en los temas de asistencia alimentaria y de protección a los menores de edad y cómo enfrentan la crisis económica alrededor de 36 millones de personas (80\%) que viven en la vulnerabilidad (9).

El documento CONPES Social 113 de 2008, define la Seguridad alimentaria y Nutricional como: La disponibilidad suficiente y estable de alimentos, el acceso y el consumo oportuno y permanente de los mismos en cantidad, calidad e inocuidad por parte de todas las personas, bajo condiciones que permitan su adecuada utilización biológica, para llevar una vida saludable y activa. Ésta definición reconoce el derecho de la población a no padecer hambre y a tener una alimentación adecuada y pone en evidencia los ejes que conforman la política, aprobados en el Conpes Social 113: disponibilidad de alimentos, acceso, consumo, aprovechamiento o utilización biológica de los mismos y calidad e inocuidad. Estos ejes generan impactos sobre la dimensión de los medios económicos, así como en la calidad de vida y el bienestar de la población (10).

\section{Subgrupo hambre- desnutrición}

Desde la perspectiva del Grupo de Trabajo de la ONU el subgrupo Hambre- desnutrición, se define como una situación de inseguridad alimentaria y de inseguridad nutricional, cuyas acciones de combate pueden ser diferentes, pero complementarias (11). En este contexto, el estado nutricional se define como la medición o la condición de salud de una persona, que expresa el grado, al cual, se satisfacen las necesidades fisiológicas de nutrientes y depende del equilibrio entre el consumo y las necesidades de los mismos. Cuando el consumo en términos de calidad y cantidad no responde a las necesidades fisiológicas, existe un balance de nutrientes negativo o positivo, que predispone a un proceso de malnutrición ya sea por déficit y se habla de desnutrición o exceso y se habla de obesidad.

Como resultado se genera la Subnutrición o insuficiencia calórica, entendida como el déficit en la cantidad diaria consumida de energía alimentaria, medida en kilocalorías por persona y día. Así mismo se presenta otra condición que es la malnutrición en adultos, que mide la relación entre peso y talla y determina tanto problemas de desnutrición como de obesidad (11).

Tanto el consumo de nutrientes como las necesidades fisiológicas están determinados por diversos factores. La intervención de uno o varios de los factores en forma desfavorable lleva a desequilibrio en el estado nutricional y por ende a alteraciones en el crecimiento, desarrollo y estado de salud de las personas. El análisis de los determinantes del estado nutricional no es un proceso sencillo, teniendo en cuenta que no existe una relación lineal entre cada uno de ellos, la mayoría se entrecruzan y/o potencian.

Las necesidades nutricionales están sujetas al estado de crecimiento, a la conservación y bienestar corporal, al stress fisiológico y psicológico, a la actividad física, a la enfermedad y a periodos fisiológicos especiales como el embarazo y la lactancia. Se plantea así un contexto general en el que todos los determinantes de estado nutricional se relacionan de alguna forma en un entorno económico, social, demográfico, ambiental y cultural (12). 
Caracterización de la desnutrición en Colombia y Bogotá, D.C.

En Colombia, tal como lo señala el grupo de investigación Asi Vamos en Salud, se observa una clara tendencia a la disminución de la desnutrición crónica y la desnutrición global. Sin embargo, llama la atención la brecha entre estos los dos indicadores, haciendo evidente la alta prevalencia de un problema que tarda por lo menos 6 meses en aparecer. Actualmente, la prevalencia de la desnutrición global está descendiendo, pasando de $8.6 \%$ en 1990 a $3.4 \%$ en 2010 estando a 0.4 puntos porcentuales de conseguir la meta fijada para el 2015.

Un descenso más pronunciado se presenta con la desnutrición crónica, que disminuyó su prevalencia en aproximadamente $49 \%$ durante los últimos 20 años. Como resultado final se observa una disminución en la brecha que separa la desnutrición crónica de la global. Lo anterior hace evidente el mejoramiento de las políticas de seguridad y prácticas alimentarias en estos grupos de edad. Asimismo, se observa que el grupo de edad con mayor prevalencia de desnutrición crónica son los niños de un año de edad y dentro de este grupo, los nińos de 10 a 11 meses.

Teniendo en cuenta que la recuperación nutricional es mucho más efectiva en este grupo de edad, se evidencia la oportunidad para la intervención de estos grupos. No obstante, cabe resaltar que de los niños que presentaron bajo peso al nacer, el $27 \%$ se encuentra actualmente en desnutrición crónica. Teniendo en cuenta que el bajo peso al nacer es una situación que se encuentra en aumento en Colombia, es sumamente importante este control a través de la divulgación de guías alimentarias y orientación en el programa de crecimiento y desarrollo para la introducción adecuada de la alimentación complementaria como estrategia para disminuir la malnutrición en Colombia.
En este escenario de análisis se procede a comparar los anteriores datos con los arrojados en el estudio ENSIN 2005-2010, capítulo Bogotá, realizado por el ICBF y Profamilia, en el que se encontró que la desnutrición crónica no retrocede en forma notoria (hace siete años afectaba al 16,9 por ciento de los menores de 5 años y ahora, con escasa diferencia, al 16,4 por ciento) lo cual significa que un total de 118.000 niños, siguen sufriendo por este tipo de desnutrición en la ciudad. La anemia en escolares se redujo al $21 \%$, mientras que la desnutrición crónica aún afecta al $16,4 \%$.

En lo que respecta a la contribución de la Subdirección de Nutrición de la Secretaría de Salud (SNSS), se destaca el compromiso de este ente público, en la realización de estudios poblacionales de carácter nacional y territorial, que le ha permitido identificar la situación nutricional de éstos, haciendo énfasis en la situación de macro y micronutrientes, especialmente hierro y vitamina A. Estos estudios en el campo de la Salud Pública, han sido importantes, dentro de la toma de decisiones en políticas nacionales, dirigidas a disminuir los problemas nutricionales del país y se han organizado a través de 3 líneas de investigación: aspecto sociocultural, situación nutricional-clínica y conocimiento básico. Con este enfoque se pretende dar una nueva orientación en lo referente a la investigación en nutrición.

Igualmente, en relación con las acciones desarrolladas por el Distrito, se enfatiza que esta entidad ha conseguido que en los últimos siete años, los escolares mejoren en el peso y que padezcan menos por anemia, ésta, según la SDS, se redujo del $36,6 \%$ en 2005 al $21 \%$ en 2010 . Por el contrario, la ciudad no ha conseguido bajar la proporción de menores de 5 años que padecen de desnutrición crónica, que es la más grave porque retrasa el crecimiento, tampoco se ha logrado reducir el alto número de personas de los 5 a los 17 años que presentan sobrepeso u obesidad. 
De hecho, en este grupo poblacional, el problema se agravó, ya que subió del 17,4\% en 2005 al 21\% en 2010. Para la epidemióloga de la U. Nacional Patricia Heredia, varios hechos explican por qué prevalece esta deficiencia nutricional. La desnutrición crónica -explicó- no es solo resultado de deficiencias en el consumo de alimentos, sino también influyen los bajos ingresos (que no permiten adquirir la comida adecuada, balanceada), la educación y las dificultades para acceder a la salud y a los servicios públicos (13).

Una vez realizada la revisión de aspectos fundamentales de la desnutrición, se revisa la fundamentación referente a la cohesión social.

\section{Antecedentes perspectiva funcionalista o no normativa frente a la Cohesión social}

El término cohesión social tiene sus orígenes en la sociología francesa dentro de la corriente funcionalista liderada por Emilio Durkheim quien proclamó que el orden social es el resultado de la solidaridad social. En su obra la división del trabajo social explica la relación directa entre la solidaridad y la división del trabajo. Enfatiza que a menor especialización del trabajo los individuos están más unidos estrechando sus lazos de amistad y esta solidaridad es mecánica. Por el contrario a mayor especialización del trabajo la solidaridad es orgánica, se debilitan los vínculos por la autonomía que adquiere el individuo en la sociedad moderna (14).

Se reconoce que el escenario descrito, caracterizado por una alta dosis de individualismo, es exclusivo de las sociedades capitalistas, que se conciben como entes política y económicamente fragmentados en razón de los intereses particulares que desvertebran la concepción y esencia natural de la sociedad, su deber ser como comunidad de intereses solidarios, lo cual contribuye a la generación de una profunda desmembración y desigualdad social.
Acorde con Bronislaw Malinowsky, representante de la antropología funcionalista, la cohesión social es fundamental en la contribución de las instituciones para el mantenimiento de la solidaridad social. Para el autor de múltiples obras, entre ellas: "Magia, Ciencia y Religión" y Los Jardines del Coral, el orden social proviene de la cooperación como producto de la conciencia colectiva. Destacó el principio de fraternidad y solidaridad entre las comunidades Melanesas, fundamentado en las creencias y ritos religiosos, la tradición, la cultura y el bienestar (15). El Kula "Es un sistema complejo que incluye relaciones sociales, comercio, intercambios tribales, ritos mágicos y leyendas. Es una institución que mantiene la cohesión social en armonía” (15).

Asimismo, se hace alusión a la contribución de Marcel Mauss, antropólogo francés que en su obra Ensayos sobre el don (1966) alude a los intercambios practicados entre poblaciones aborígenes. Se refiere al sistema de trueque generalizado de retribución y distribución de bienes simbólicos y materiales, lo cual significa, que existe reciprocidad. Dentro de esta línea denominada perspectiva no normativa se ubican los sociólogos Pierre Bordieu, James Coleman y Robert Putnam quienes hacen alusión al concepto de capital social como una forma de cooperación, caracterizada por solidaridad, confianza, y que se orienta al bien común.

En el contexto del presente artículo, esta entidad no normativa, estaría conformada por patrones básicos de cooperación social y un conjunto de valores colectivos (16), que funcionan como una estructura vinculante En esta perspectiva una sociedad altamente cohesiva, bien organizada y con altos niveles de confianza no tiene por qué ser igualitaria, puede ser compatible con un estado mínimo, en una economía de libre mercado, en la que asegurar que todos los ciudadanos sean incorporados al mercado (no integrados en un sentido amplio) implica un bajo costo para la sociedad (16). 
En el núcleo de esta conceptualización está la inserción social de los pobres en el mercado, no su incorporación a la sociedad como ciudadanos en un sentido pleno como el que imaginaba Marshall. Por ello, es evidente que esta noción sigue el modelo liberal o residual de cohesión social. Sin embargo, como lo ha señalado Woolcock (1998) esta perspectiva deja de lado una serie de factores socio estructurales, que interfieren con la cohesión social, entre ellos: las matrices de desigualdad social que tienen su asiento en relaciones de clase, sexo, etnia, cultura y creencias; de lo anterior se deduce que el origen de la cohesión social se ubica en sociedades no capitalistas donde prima la identidad y el sentido de pertenencia y no se rigen por el concepto utilitarista.

\section{Cohesión social en el contexto de la comunidad europea}

En el caso Europeo se menciona que el concepto de Cohesión Social es muy impreciso y que la búsqueda de cohesión social, se pretende a través de la estabilidad política y económica, mediante la uniformidad de la moneda. El Artículo 2, del Tratado Constitutivo de la Comunidad Europea (conocido como el Tratado de Maastricht), suscrito en Roma en 1959, se limita a propugnar el desarrollo armonioso, la expansión continua y equilibrada (15).

En el artículo 23, este tratado enfatiza que la Unión Europea tiene como objetivo desarrollarse armoniosamente y que para ello debe reducir las diferencias entre los niveles de desarrollo de las diversas regiones. No obstante, no precisa una definición más amplia que dé cuenta de las estrategias que pretenden seguirse para su aplicación en las políticas públicas.

Recientemente, el glosario de la Unión Europea ha señalado que la cohesión económica y social constituye una expresión de la solidaridad entre los Estados miembros y las regiones de la Unión Europea, por tanto favorece el desarrollo equilibrado del territorio comunitario, la reducción de las diferencias estructurales entre las regiones de la Unión y la verdadera igualdad de oportunidades entre las personas (15).
A pesar de no tener un concepto claro, preciso y desarrollado sobre la cohesión social, la Unión Europea ha establecido algunos indicadores que permitan medir la cohesión en el conjunto de países y definir algunas políticas públicas, entre éstos destaca:

- Desigualdad en la distribución de los ingresos.

- Tasa de riesgo de pobreza, antes de transferencias sociales (total y por sexo).

- Tasa de riesgo de pobreza, después de transferencias sociales (total y por sexo).

- Tasa de riesgo de persistencia de pobreza (total y por sexo).

- Dispersión de las tasas de empleo regional Jóvenes que dejan prematuramente la escuela (total y por sexo).

- Tasas de desempleo de larga duración (total y por sexo).

- Población en los hogares de desempleados (niños, total y por sexo).

\section{Perspectiva normativa de la Cohesión Social}

Se advierte asimismo, que en el marco de las negociaciones comerciales entre América Latina y Europa, se propuso como requisito el tema de la promoción de la cohesión social. Sin embargo, la integración armoniosa de la sociedad aparece como una utopía funcionalista, imposible de alcanzar, si se tienen en cuenta las diferencias y desigualdades sociales, económicas y políticas, reconociendo que las sociedades modernas no sólo son pluralistas sino desiguales.

Así, una visión normativa más realista ha relacionado el tema con la construcción de relaciones sociales, económicas y políticas mediadas por reglas e instituciones públicas, que no intentan lograr la asimilación (procesos propios de sociedades pre modernos) sino evitar la polarización. Los métodos implican siempre mediaciones institucionales y pueden variar, se puede regular, mercantilizar, educar o democratizar a la sociedad, los mecanismos considerados son diversos: el estado, el mercado, la familia o las instituciones de la sociedad civil (16). 
En todo caso, en este escenario se asume que los estados nacionales son capaces, con diversos grados de éxito, de desarrollar alguna forma de cohesión combinada con sistemas de autoridad (que descansan en normas y mecanismos coercitivos para intentar garantizar el orden social y generar legitimidad social, mixtura que permite que las sociedades se reproduzcan). De ahí, que resultaría interesante analizar el contexto reciente de la Unión Europea, en relación con la crisis económica actual, la masiva migración, la multiculturalidad, el terrorismo, entre otros aspectos, con lo que seguramente tendrán que replantearse las políticas de cohesión social.

De acuerdo con Robert Castell (1997) el tema central durante el siglo XX, fue la creación de la figura del trabajador asalariado moderno, quien expresa las disfuncionalidades de las sociedades modernas en los albores del capitalismo, donde el orden jurídico político se basaba en el reconocimiento de derechos y libertades, mientras el ámbito económico se caracterizaba por la miseria y la indigencia, por ello, este hiato, fue uno de los factores cruciales para pensar el tema de la cohesión social, que expresaba la necesidad de crear primero leyes de pobres e instituciones de asistencia y posteriormente un sistema de bienestar ligado a derechos sociales para contrarrestar la imposibilidad del orden autorregulado del mercado.

Se podrían delinear distintas formas de cohesión social que priman en la actualidad en los países postindustrializados. En el primer caso, cohesionar la sociedad implica reducir la desigualdad a través de procesos redistributivos; en el segundo, conlleva a mercantilizar el trabajo; mientras que en el tercero, involucra segmentar a la sociedad a través de procesos específicos de reciprocidad. En cada caso, la forma dominante de Cohesión Social, es una respuesta política a los problemas de integración social de las sociedades modernas (17).
La visión normativa, considera que construir Cohesión Social requiere una amplia intervención estatal en la búsqueda de justicia social y reducción de desigualdades y que ello exige, además de acciones redistributivas por parte del Estado, un alto costo fiscal para la sociedad en su conjunto. Para esta noción, que sigue el modelo socio demócrata, lo fundamental es la desmercantilización del bienestar social a través de la construcción de un entramado de derechos universales que permitan desvincular el bienestar de los ciudadanos de su situación en el mercado (18).

Acorde con Sorj Y Martuccelli (2008) la actual noción de cohesión social, no tiene nada que ver con la corriente funcionalista, es fundamentalmente una referencia normativa asociada a criterios operacionales, que le apuestan al bienestar y calidad de vida como lo son, entre otros aspectos: la salud, los ingresos, el empleo, los Indicadores de Desarrollo Humano (IDH).

En este enfoque normativo, la cohesión social tiene tres dimensiones: la equidad, el capital social democrático y la titularidad de derechos sociales. Las dos primeras se materializan a través de la reducción de la desigualdad y el reconocimiento de las diferencias, lo que conlleva al fortalecimiento de las relaciones sociales y la confianza en las instituciones democráticas. La tercera, referida a la titularidad de derechos sociales, constituye la manera más universal y democrática de promover la cohesión social.

\section{Titularidad de los derechos sociales}

La razón de los derechos sociales, como la educación, el derecho al trabajo y a la salud, es una razón igualitaria, puesto que tiende a reducir la desigualdad entre quienes tienen y en quienes nada tienen, $o$ a poner un número de individuos siempre mayor, en condiciones de ser menos desiguales con respecto a un número mayor de afortunados por nacimiento, o por condiciones socioeconómicas (19). 
Jhon Rawls (1971) afirma que una sociedad justa implica considerar a cada persona como digna y moral, lo que significa también que una sociedad puede garantizar el acceso político de todos, a ciertos bienes sociales tales como: derechos, libertades, ingresos, para tener una vida digna, decente, que lo habilite para poder participar en los fundamentos básicos de las relaciones colectivas y así promover la autoestima individual, aspecto importante en el impulso de la eficacia económica habida cuenta que ésta debe subordinarse a esta práctica política de libertades e igualdad de oportunidades.

Acorde con Salvat (2004) esto no significa tampoco la supresión de toda desigualdad, sino un ideal de sociedad, en el que sus instituciones centrales sean capaces de encarnar estos principios de justicia social, en la cual sus miembros se adhieran a estos principios que sostienen a las instituciones y actúen en concordancia con ellos. La titularidad de los derechos sociales significa que el Estado brinde a todos los ciudadanos un mínimo de condiciones necesarias para su logro. Los ciudadanos se sienten incluidos en la sociedad, cuando el Estado por medio de las políticas públicas, es capaz (de manera deliberada) de controlar la obligación económica social dialéctica que le asiste, en cuanto a reducir los críticos niveles de exclusión social existente.

En esta medida, la cohesión social le apuesta a la inclusión; tiene un valor práctico y ético porque aporta ciudadanía, sentido de pertenencia, fortalece la solidaridad y responsabilidad social, mejora la confianza en las instituciones facilita los pactos sociales suscritos con el Estado y la sociedad civil, refrendados (estos pactos sociales) con pactos fiscales, estableciendo los mínimos aceptables que involucra el conjunto de la sociedad incluyendo a los grupos vulnerables, en términos de acceso al desarrollo y a la dinámica de bienestar que este brinda (20).

El modelo de bienestar Europeo se caracteriza por la permanente preocupación en avanzar hacia un Estado de bienestar social y residual, donde la variable dependiente es el gasto social; cuanto más desarrollado e institucionalizado es el bienestar mayor es el gasto social.

Acorde con Richarrd Titmuss (1998), surgen otros modelos de bienestar social, tales como el redistributivo (democrático liberal), el de rendimiento (conservador corporativista) y el Residual (Liberal). En este escenario, se presenta como ejemplo, el $\mathrm{Mo}$ delo Escandinavo de bienestar catalogado como universal y costoso, el cual está financiado con cargo a impuestos, existe provisión pública de transferencias y servicios sociales de buena calidad, representa una alta participación ciudadana en el mercado laboral, se caracteriza por la universalidad, sistema de prestaciones sociales, derechos de ciudadanía social, doble ingreso por hogar, políticas laborales activas y servicios sociales amplios, política tributaria y pleno empleo. (Los tres mundos del capitalismo The three worlds of Welfare capitalism (21).

En el Seminario de la CEPAL (2010), Barba Solano introduce el tema de la cohesión social aduciendo el carácter polisémico del concepto que deriva no sólo de la imposibilidad de lograr un consenso amplio sobre su significado, sino de la tendencia que prevalece a asociar este concepto con una idea de armonía social que resulta inaceptable en el Contexto Latinoamericano caracterizado por enormes desigualdades, pobreza masiva y procesos históricos (y otros nuevos) de exclusión socioeconómica y sociocultural. Barba subraya la necesidad de vincular desigualdad y cohesión social, para pensar sobre los problemas de integración social en América Latina y rechaza la versión hegemónica de cohesión social, que suele reducirla a la posibilidad de lograr que los más pobres se inserten en el mundo del mercado.

Afirma que la cohesión social, se inscribe como estrategia para encarar diversos problemas tales como los altos índices de pobreza e indigencia, la desigualdad extrema y las diversas formas de discriminación y de exclusión social, cuya profundización ha estado en relación directa con la dinámica de la economía global. 
Para Sorj y Martuccelli (15) la noción actual de cohesión social no tiene afiliación con la corriente de la sociología funcionalista "es fundamentalmente una referencia normativa asociada a criterios operacionales en torno a indicadores (empleo, salud, educación) que son seleccionados por el debate público, los políticos y las asociaciones defensoras de los derechos humanos, civiles y fiscales, entre otros".

\section{Indicadores cuantitativos de la cohesión social según Laeken}

- Ingreso y pobreza (Ingreso con respecto del nivel de la línea de pobreza; población en indigencia; relación entre el quintil + rico y el quintil + pobre de la población antes y después de las transferencias por la aplicación de la política social).

- Empleo (Tasa de desempleo abierta; tasa de desempleo de baja duración; Porcentaje de la población ubicada en sectores de baja productividad).

- Educación (Matricula en edad preescolar; porcentaje de la población mayor de 15 años que no cursó educación preescolar; gasto del Estado versus gasto de la población con altos ingresos).

- Salud (Esperanza de vida al nacer; mortalidad infantil; mortalidad en niños menores de 1 año) (22).

\section{Indicadores cualitativos de la cohesión social según la CEPAL}

- Pertenencia se refiere a los niveles de Confianza, participación, expectativas con respecto del futuro, valores y normas compartidas.

- Inclusión se refiere al Acceso a los canales de participación, confianza y respaldo al orden social.

- Ciudadanía teniendo en cuenta la Integración a la sociedad, y las posibilidades de autodeterminación).

- Solidaridad conforme a las relaciones de convivencia, conciencia colectiva y responsabilidad social.

\section{Indicadores hambre-desnutrición según el ICBF y Pro familia}

- Desnutrición (Cantidad y calidad de micronutrientes consumidos, absorción biológica acorde con la necesidad fisiológica).

- Subnutrición (déficit en la cantidad diaria consumida de energía alimentaria, medida en kilocalorías por persona y día).

- Subnutrición en niños menores de 5 años: crónica (retardo talla para la edad).

- Aguda o global (retardo peso para la edad).

- Malnutrición adultos (índice de masa corporal que mide la relación entre peso y talla).

- Percepción de la inseguridad alimentaria en los hogares (Diversos factores intervinientes).

\section{Materiales y métodos}

Para el desarrollo de la propuesta se usaron los siguientes instrumentos de recolección de información:

- Fuentes primarias (artículos de investigación originales, de revistas indexadas, nacionales e internacionales).

- Fuentes Secundarias (artículos de investigación con análisis de los autores, revistas indexadas, nacionales e internacionales).

Con la información recolectada se pasa a la segunda etapa del método que corresponde a:

- Revisión y análisis de los indicadores cuantitativos y cualitativos de cohesión social.

- Revisión y análisis de los indicadores sociales de la calidad de vida.

- Revisión y análisis de los indicadores sociales de la salud -desnutrición. 


\section{Resultados y discusión}

Con fundamento en la revisión bibliográfica realizada frente a los tres determinantes que direccionan el presente trabajo cuales son: análisis de situaciones de pobreza como factor de riesgo para la

Gráfica 1. Incidencia de la pobreza por departamentos 2012

\section{Linea de Pobreza por departamentos y Bogotä D.C 2012}

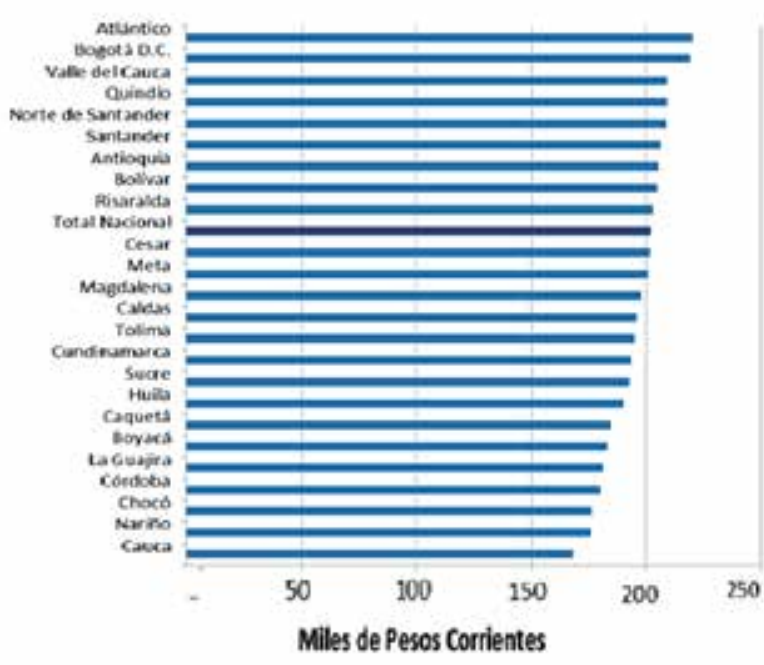

Fuerte: OANE, coloulos con tase GEH,

La línea de pobreza nacional a diciembre del año 2012 se sitúo en \$202.083. El grafico 1 muestra que la mayor línea de pobreza se presenta en el departamento de Atlántico con $\$ 220.510$, línea que está $\$ 18.427$ sobre el valor de la línea de pobreza nacional, y la menor línea de pobreza está en el departamento del Cauca con $\$ 168.312$, la cual está $\$ 33.771$ bajo el valor de la línea de pobreza nacional. En lo concerniente a variación porcentual con respecto al año inmediatamente anterior, el departamento con mayor crecimiento fue Santander con el $4.9 \%$, mientras la menor variación fue en Bogotá D.C. con el 3.0\%.

La incidencia de la pobreza es el porcentaje de personas que son clasificadas como pobres, por lo tanto permite observar la relación de individuos pobres con respecto a la población total por departamento. Los resultados para el ańo 2012 muestran un nivel de incidencia nacional en el 32.7\%. Los departamentos con menor nivel de incidencia de la pobreza son, Bogotá desnutrición y estos dos componentes con incidencia frente a la posibilidad de encontrar cohesión social, se presentan los resultados de los niveles de pobreza, condiciones de desnutrición e indicadores de cohesión social.

Gráfica 2. Línea de Pobreza por departamentos y Bogotá D.C. 2012

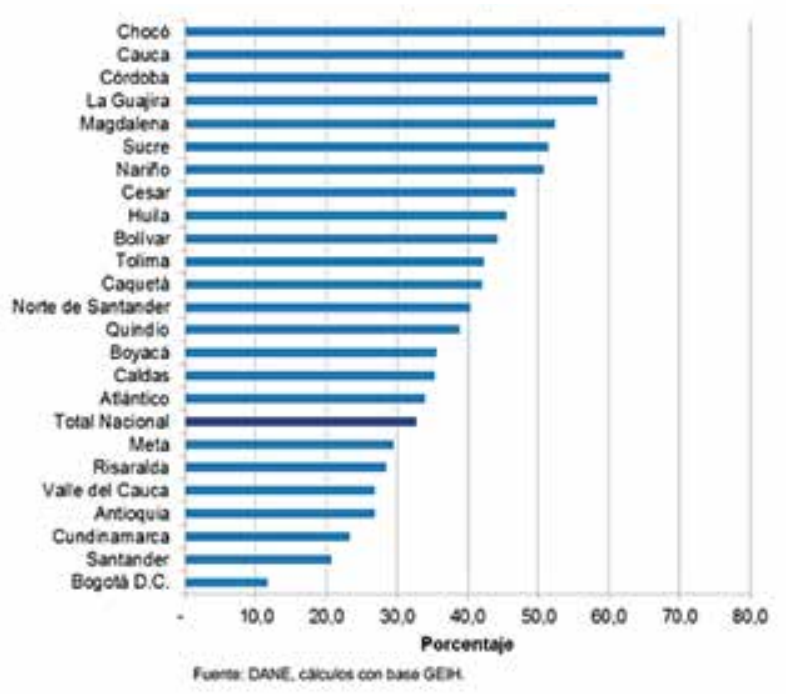

D.C. con $11,59 \%$, Santander con el $20,8 \%$, Cundinamarca con el 23,3\%, Antioquia con el 26,8\% y Valle del Cauca con el 26,9, todos los anteriores presentaron nivel de incidencia inferior al nacional, mientras los departamento con mayor nivel de incidencia de la pobreza son Chocó con el 68,0\%, Cauca con el 62,1\%, Córdoba con el 60,2\%, y La Guajira con el 58,4\%.

Gráfica 3. Distribución de Hogares por tipo de pobreza

Bogota 0.C. Distribución de los hogares por tipo de pobreza según MIP tradicional (LP.NBI), por estrato. 2011

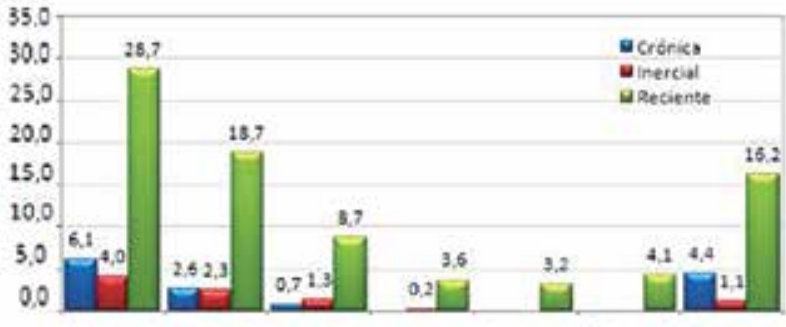

Estrato 1 Estroto 2 Estrato 3 Estrato 4 Estroto 3 Estrato 6 Estrato 9 
Se aprecia la distribución de los hogares por tipo de pobreza: hogares con pobreza crónica o pobreza prolongada, es decir que viven con menos de una necesidad básica insatisfecha es del 1.8\% y con pobreza inercial o que potencialmente pueden superar sus necesidad básicas es del 1.7\%. Se evidencia que en los estratos 5 y 6 solo se presenta la pobreza reciente, es decir que se presenta por ingresos insuficientes pero viven con todas las necesidades básicas satisfechas. Mientras en los estrato uno y dos, la crónica tiene niveles del $6.1 \%$ y del $2.6 \%$ respectivamente.

Gráfica 4. Bogotá D.C. Porcentaje de hogares en pobreza crónica según MIP tradicional (NBI-LP), por componentes, según estrato, 2011

\section{Bogotá D.C. Porcentaje de hogares en pobreza crónica según MIP tradicional (NBI-LP), por componentes, según estrato. 2011}

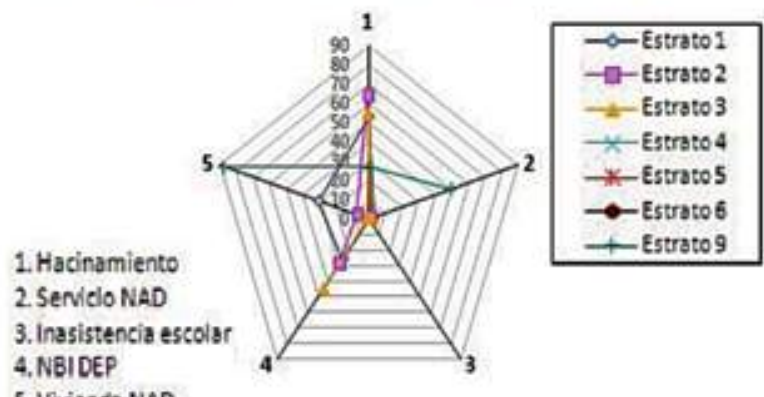

5. Vivienda NAD

Fuente: DANESDP. Encuesta Mulfproposito de Bogota 2011. Caloulos SOP: SIEE-DEM

\begin{tabular}{|c|c|c|c|c|c|}
\hline Ettrato & $\begin{array}{l}\text { Hxins. } \\
\text { miento }\end{array}$ & $\begin{array}{l}\text { Senvicios Inaistenia } \\
\text { ingdecuados escolar }\end{array}$ & $\begin{array}{c}\text { Alta } \\
\text { dependencia }\end{array}$ & $\begin{array}{l}\text { Viviendr } \\
\text { insdecuads }\end{array}$ & $\begin{array}{l}\text { Iegresesos } \\
\text { premedio' }\end{array}$ \\
\hline Estrato! & 53,2 & 2,8 & 25,5 & 30,4 & 121019 \\
\hline Estato? & $64:$ & 16 & 290 & 68 & 125362 \\
\hline Estrato 3 & 55,2 & 2,4 & 44,6 & 0,8 & 143.473 \\
\hline Estrato 4 & & & & & \\
\hline
\end{tabular}

\section{Estrato5}

\begin{tabular}{|lrrrrr|}
\hline Estrato6 & & & & & \\
\hline Estrato9 & 26,7 & 49,9 & & 87,3 & 75.000 \\
\hline Total Bogoti & 58,7 & 3,6 & 29,4 & 15,0 & 125.178 \\
\hline
\end{tabular}

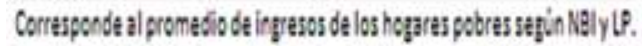

Fuente: OANESOP. Encuesta Muliproposilio de Bogotat 2011. Callaulos SOP: SIEE. DEM
De los hogares que presentan pobreza crónica, o que se encuentran con al menos una NBI y con insuficiencia de ingresos, el estrato que presenta mayor hacinamiento es el estrato 2 con el $64.2 \%$ de los hogares, seguido por el estrato uno con el 53.2\%, para este último se destaca la vivienda inadecuada en el $30.4 \%$ de los hogares. Mientras en el estrato 3 la dependencia económica es del $30.4 \%$, en el estrato 4 solo el $0.1 \%$ de los hogares presenta pobreza crónica, principalmente por las variables educación y trabajo, en el estrato 5 y 6 no hay hogares con este nivel de pobreza.

Gráfica 5. Bogotá D.C. Porcentaje de hogares en pobreza inercial según MIP (NBI-LP), por componentes, según estrato, 20111

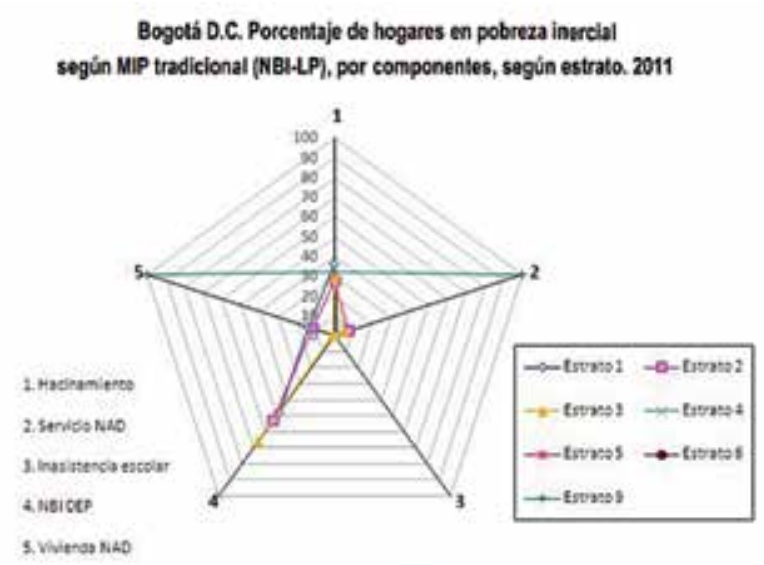

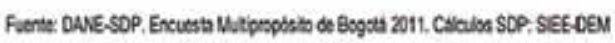

\begin{tabular}{|c|c|c|c|c|c|}
\hline Estrato & $\begin{array}{l}\text { Hacinz. } \\
\text { miento }\end{array}$ & $\begin{array}{l}\text { Servicios } \\
\text { inadecuados }\end{array}$ & $\begin{array}{l}\text { Inasistenia } \\
\text { escolar }\end{array}$ & $\begin{array}{c}\text { Alta } \\
\text { dependencia }\end{array}$ & $\begin{array}{l}\text { Vivienda } \\
\text { inadecuada }\end{array}$ \\
\hline Estrato 1 & 36,5 & 1,6 & & 48,0 & 13,9 \\
\hline Estrato & 27,7 & 7,5 & & 53,4 & 11,3 \\
\hline Estrato 3 & 30,6 & 4,9 & & 66,6 & 0,9 \\
\hline Estrato 4 & & & & 1000 & \\
\hline \multicolumn{6}{|l|}{ Estrato 5} \\
\hline \multicolumn{6}{|l|}{ Estatato 6} \\
\hline Estratog & 32,1 & 100,0 & & & 100,0 \\
\hline Total Bogotá & 29,8 & 6,4 & & 56,1 & 9,6 \\
\hline
\end{tabular}

Fuente: DANE-SDP. Encuesta Multipropósito de Bogotá 2011. Cáluulos SDP: SIEE.DEM 
De los hogares con pobreza inercial, o que tienen alguna necesidad básica insatisfecha pero que tiene ingresos sobre la línea de pobreza, se destaca la dependencia económica, para Bogotá esta variable fue del $56.1 \%$ de los hogares con este nivel de pobreza. En el estra- to 4 todos los hogares con nivel de pobreza inercial son por la variable dependencia económica.

Según los estudios en Vigilancia en Salud Pública reportados por la Secretaria de Salud, se encontraron las siguientes situaciones:

Gráfica 6. Prevalencia de desnutrición crónica en menores de 5 años Colombia 1990-2010

\section{Prevalencia de desnutrición crónica en menores de 5 años Colombia 1990-2010}

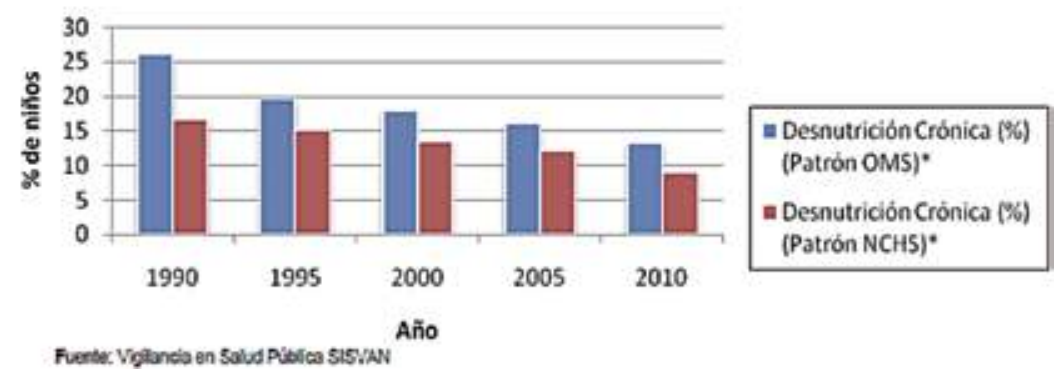

Desde el año 1990 la desnutrición crónica en menores de 5 años ha disminuido notablemente, para el año 2010 este nivel se sitúa alrededor del 12\% según patrones de la OMS, donde se define como desnutrido a aquel niño que se encuentra por debajo de dos Gráfica 7. Porcentaje de desnutrición crónica en niños y niñas de 0 a 17 ańos. Bogotá, 2005-2010

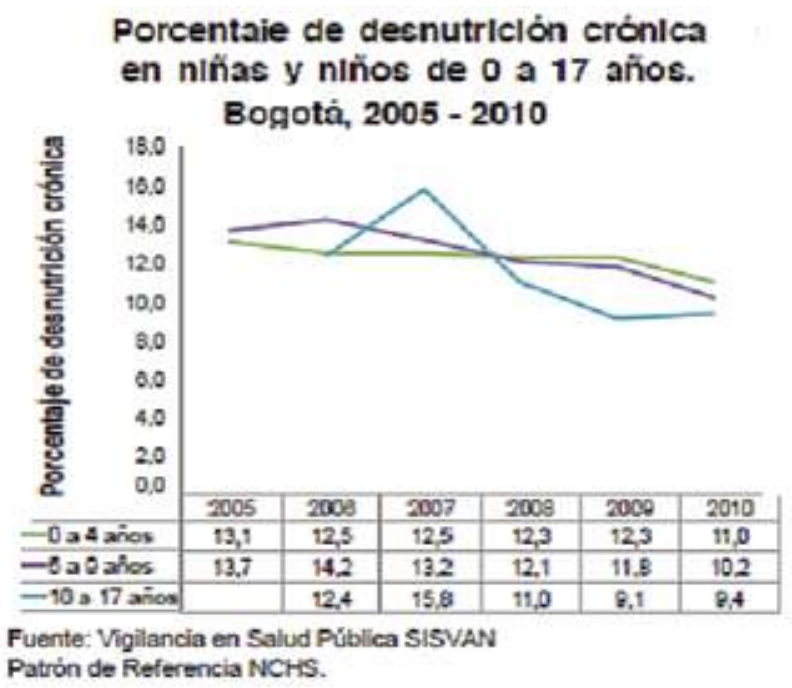

desviaciones estándar de la mediana de las curvas de referencia NCHS y un poco menos del $10 \%$ en la desnutrición crónica con patrón NCHS que proviene de las tablas de crecimiento del Centro Nacional de Estadísticas de Salud de los Estados Unidos.

Gráfica 8. Porcentaje de desnutrición global en niños y niñas de 0 a 9 ańos. Bogotá, 2005-2010

Porcentaje de desnutriclón global en nlñas y nlños de 0 a 8 años. Bogotá, $2005=2010$

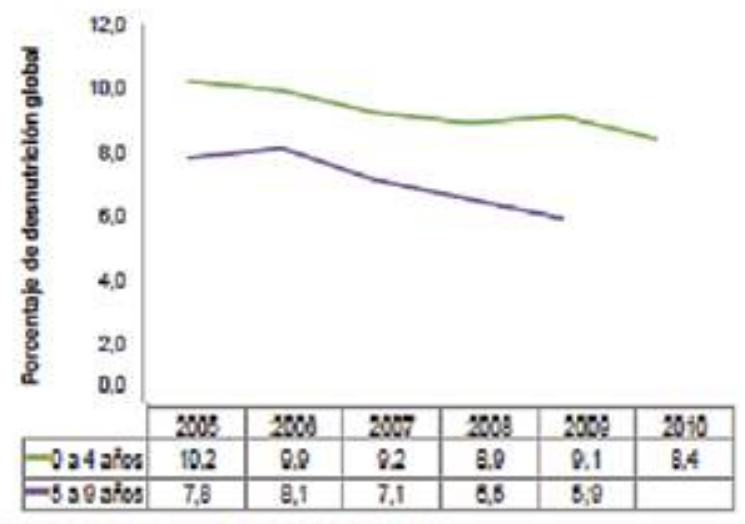

Fuente: Vigilancia en Salud Pública SISVAN Patrón de Referencia NCHS. 
El gráfico 7 muestra con el patrón NCHS, para el año 2010, el porcentaje de niños menores de 5 años con nivel de desnutrición es del $11 \%$, porcentaje superior al de los niños entre 5 y 9 años que se sitúa en el $10.2 \%$ y el porcentaje de desnutrición crónica en niños con edad superior al a los 9 es del 9.4\% años se destaca la caída de las tasas de participación en el periodo 2009-2010.

Gráfica 9. Porcentaje de desnutrición aguda en niños y niñas de 0 a 9 años. Bogotá, 2005-2010

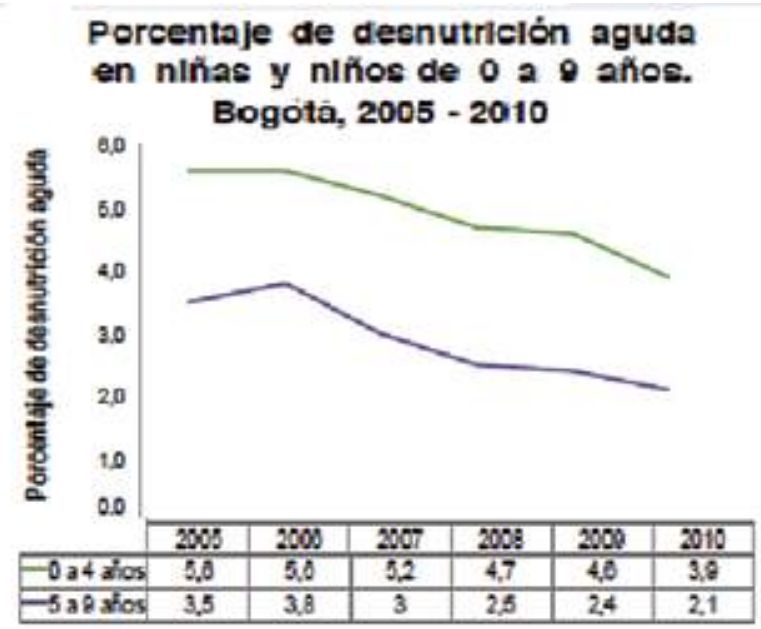

Fuente: Vigllancia en Solud Públiea SISVAN Patrón de Referencia NICHS.

En el grafico 9, en lo concerniente a nivel global y continuando con el patrón de referencia NCHS para la medición de desnutrición, el porcentaje de niños menores de 5 años con desnutrición aguda fue del 3.9\% para el año 2010, siente puntos porcentuales por debajo del nivel para el año 2009. Mientras el porcentaje de desnutrición en niños de 5 años en adelante se situó en el $2.1 \%$ en el año 2010 solamente tres puntos porcentuales por debajo del año 2009.

En el grafico 10, en el año 2010 por cada cien mil menores de cinco años, la mortalidad por desnutricion fue de 0.8 , tasa muy inferior a la del año 2009 que fue del 2.5, se destaca la caida de la tasa desde al año 2005, año para el cual se situaba en el 5 muertes de menores de cinco ańos por cada cien mil.
El grafico 8 muestra la distribución global con el patrón NCHS de la desnutrición en niños y niñas menores de 5 años, que se sitúo al año 2010 en el 8.4\%, siete puntos porcentuales por debajo del valor para el año 2009. El porcentaje de desnutrición global para los niños entre cinco y nueve para el año 2009 fue del $5.9 \%$, se resalta la caída constante del porcentaje de desnutrición en este último rango de edades.

Gráfica 10. Tasa de mortalidad por desnutrición por 100.000 menores de cinco ańos. Bogotá, 2005-2010

\section{Tasa de mortalidad por desnutrición por 100.000 menores de clnco años.} Bogotha, 2005 - 2010

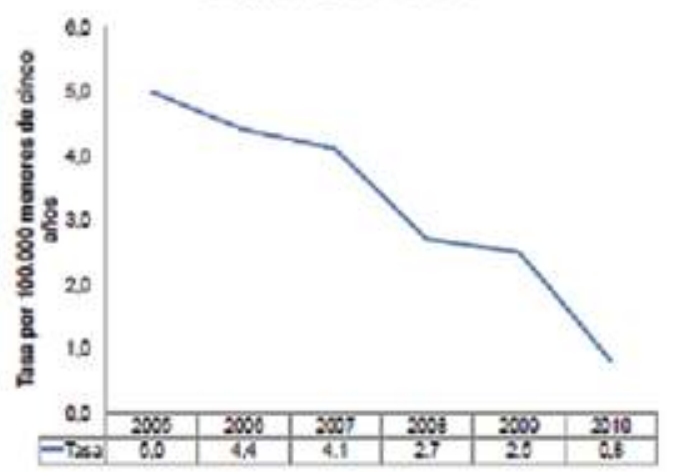

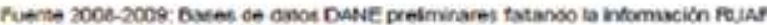
Fuerte 2010-2C11: Cases de datos detundiones SOS.

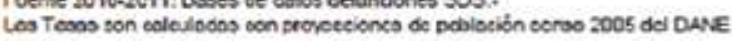

\section{Pobreza-Desnutrición}

Los esfuerzos realizados han contribuido a disminuir los niveles de pobreza en la región de A.L. y el Caribe, donde se redujo el número de personas afectadas por el hambre (de 54 millones 2005 a 49 millones 2010 y 2012). Sin embargo, ésta sigue siendo una situación preocupante y que lesiona todavía la calidad de vida de su población, como lo demuestran las gráficas de los estudios realizados entre otros por el DANE, PNUD, BANCO MUNDIAL, OCED, CEPAL, si bien es cierto que en algunas regiones de Colombia se ha mejorado la situación, otras siguen presentando estados críticos, cual es la región chocoana, la región de Nariño y la del Cauca. 
Especialmente, es preocupante observar la distribución de los hogares por tipo de pobreza, según MIP por estrato en Bogotá (2011): 28.7 en estrato $1 ; 18.7$ para estrato 2 y 16.2 para estrato 9 , indicativos de una nueva realidad difícil para muchas familias. En Colombia, según el DANE, el $34,1 \%$ de los colombianos vive en la pobreza y otro $10,6 \%$ en la indigencia. Si estas cifras se comparan con los datos de la última Encuesta ENSIN, publicada en 2010 , según la cual el $42 \%$ de los hogares del país padece hambre, se confirma que la pobreza y la mala nutrición van de la mano, debido a las condiciones precarias tanto alimentarias, sanitarias, habitacionales, falta de información y condiciones ambientales negativas.

Además de esta situación, la salud pública en los países subdesarrollados tiene graves carencias como hospitales y centros médicos superpoblados y por ende grandes demoras para que los pacientes sean atendidos, falta de insumos e infraestructura adecuada, insuficiencia de profesionales entre otros aspectos. Toda esta realidad hace que los pobres se vean muy afectados en su salud, en la efectividad de los tratamientos y por consiguiente la recuperación por una patología se dificulta.

Frente a esta revisión se deduce que la pobreza reduce la expectativa de vida de nińos, madres, ancianos, hombres y jóvenes, así como disminuye notablemente la calidad de la misma. Para los estados locales y nacionales debe ser una prioridad la salud pública en todo su aspecto preventivo como paliativo, porque se reconoce que es función del Estado asegurar calidad en la oferta de salud para los individuos.

El derecho a la salud es un derecho humano de gran importancia y alcance, ya que protege la propia vida, por tanto, el servicio de salud debe tener disponibilidad, accesibilidad, aceptabilidad y calidad para todos los integrantes de la comunidad sin importar su condición económica. Para que sea pleno el respeto de este fundamental derecho, es importante que los países desarrollados ayuden y colaboren a mejorar la salud pública en los países menos desarrollados.

La lucha contra la pobreza se centra en el crecimiento económico que es el arma más poderosa para mejorar la calidad de vida, derivada de la distribución del ingreso y la riqueza (PIB). Dentro de las prioridades se resaltan el acceso a la educación, al agua potable, a la salud e inmunizaciones para las poblaciones vulnerables, resaltando la población infantil.

El desarrollo humano no concluye ahí, otras opciones a las que muchas personas asignan gran valor, van desde la libertad política, económica y social hasta las oportunidades para disfrutar de una vida creativa, productiva y gozar del respeto por sí mismo y de la garantía de los derechos humanos; por ello, el desarrollo social requiere de programas y políticas públicas, encaminadas a la protección de los hogares pobres, en pro de que estos alcancen una mayor capacidad y niveles de bienestar social.

Es así como le corresponde al Estado como garante de la justicia social y de la reducción de desigualdades sociales, procurar una menor volatilidad y periodos de crecimiento sostenidos en la creación de empleo formal y acceso de estas poblaciones vulnerables a mecanismos de protección y de fuentes sostenibles de ingreso.

Se presenta el círculo vicioso de la pobreza determinado por OMS 2010 que indica:

- Pobreza

- Desnutrición

- Mala atención sanitaria

- Alta mortalidad infantil

- Fertilidad elevada

- Analfabetismo

- Falta de capacidades

- Desocupación

- Endeudamiento crónico 
En el Grafico 11 se aprecia la tasa de fecundidad para Bogotá en el periodo 2005- 2010 y dentro de este aspecto, es de tener en cuenta el crecimiento de las tasas de fecundidad en adolescentes, situación que se torna en un problema por las consecuencias que conlleva.

Gráfica 11. Tasa de fecundidad por localidad. Bogotá, 2005-2010

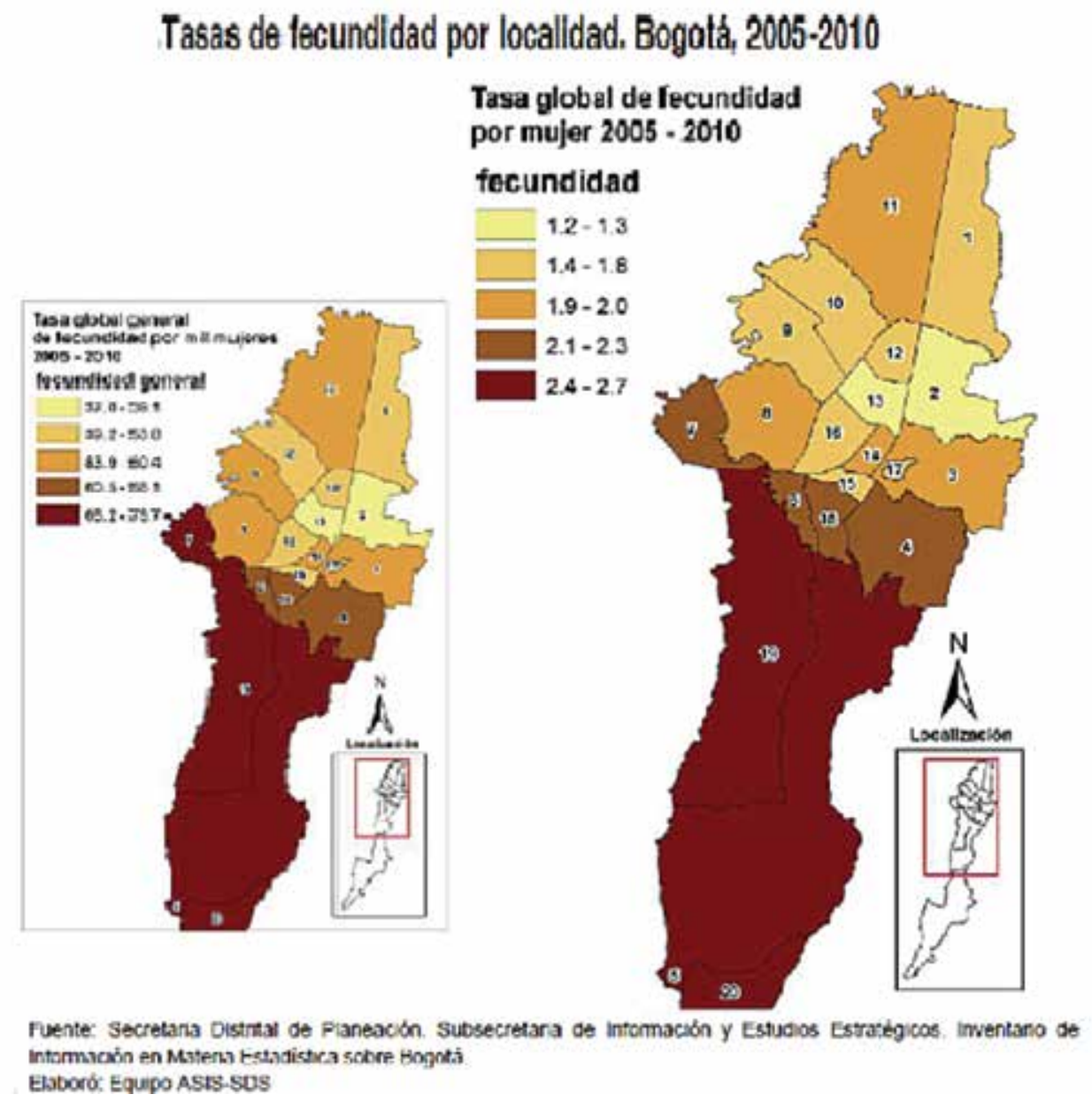

Teniendo en cuenta el impacto de la pobreza en la desnutrición, se tomó este indicador como eje de la problemática de la pobreza y se observa en las gráficas, que si bien es cierto ha disminuido en uno o dos puntos porcentuales, los valores siguen siendo representativos de la problemática al respecto. La esperanza de vida al nacer ha mejorado los niveles, pero el ideal es mejorar aún más.
La prevalencia de bajo peso al nacer se ha visto incrementada, quizás debido a los altos índices de embarazo en las adolescentes, que no tienen los cuidados nutricionales exigidos para un buen embarazo y una buena gestación. En este mapa se aprecia la representación de embarazos en adolescente. 


\section{Cohesión social}

En cuanto a la cohesión social se presentan los componentes y dimensiones de la cohesión social:

Tabla 1. Indicadores de distancia

INDICADORES DE DISTANCL (FASE EXPLORATORIA)

\begin{tabular}{|c|c|c|}
\hline DIIENSIÓx & INDICADORES PRDLARIOS & INDICADORES SECUNDARIOS \\
\hline $\begin{array}{c}\text { Ingresos y } \\
\text { potreza }\end{array}$ & 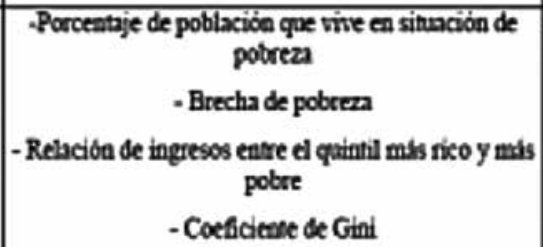 & $\begin{array}{l}\text { Porcentaje de poblacióa que vive en situnción } \\
\text { de indigencia } \\
\text {-Brecha de indigescia }\end{array}$ \\
\hline Empleo & $\begin{array}{l}\text {-Tasa de destempleo abiento } \\
\text { - Porcentaje de población ocupada que trabaja en } \\
\text { sectores de baja productividad }\end{array}$ & -Tasa de destempleo de large duacide \\
\hline Educación & $\begin{array}{l}\text {-Tasa neta de matricula en educacióa pre-escolar } \\
\text {-Porcentaje \&e mayores \&e } 15 \text { alios que no han } \\
\text { terminado la primaria } \\
\text {-Porcentaje \&e mayores \&e } 20 \text { ados que no han } \\
\text { terminado la secundaria }\end{array}$ & $\begin{array}{l}\text {-Gasto estatal por alumno en la educación } \\
\text { pistica comparado con el gasto por alumno \&e } \\
\text { las familias de chase media-alta }\end{array}$ \\
\hline Salnd & $\begin{array}{c}\text {-Esperanas de vida al nacer } \\
\text { - Tasa de mortalidad infantil } \\
\text {-Porcentaje de partos atendidos por personal } \\
\text { samitario especializado }\end{array}$ & $\begin{array}{l}\text {-Propercion de nithos menores \&e un ato } \\
\text { immunizalos contra las } \\
\text { tres eafermedades mis relevaetes para cadh } \\
\text { pais }\end{array}$ \\
\hline Vivienda & \multicolumn{2}{|c|}{$\begin{array}{l}\text { Porcenhaje de pobbación con acceso a sistemas mejorados de saneamiento } \\
\text { - Porcentaje de viviendas precarias respecto al toeal \&e viviendas }\end{array}$} \\
\hline Pensiones & \multicolumn{2}{|c|}{ 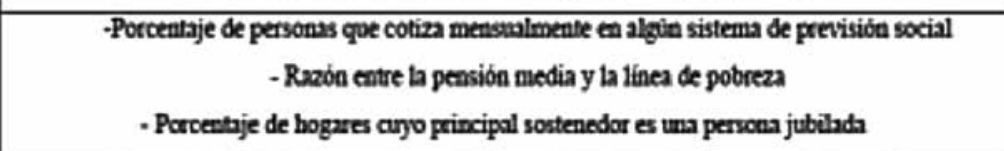 } \\
\hline Brecha digial & \multicolumn{2}{|c|}{-Acceso de nitios y jóvenes a courputadoras e Internet, en el hogra y en la escuela } \\
\hline
\end{tabular}

Fwente: Elaboracion propia, en base a CEPAL (2007).

Tabla 2. Componentes y dimensiones de la cohesión social

COMPOXEXIES Y DLMEXSIOXES DE LA COHESTOX SOCLAL.

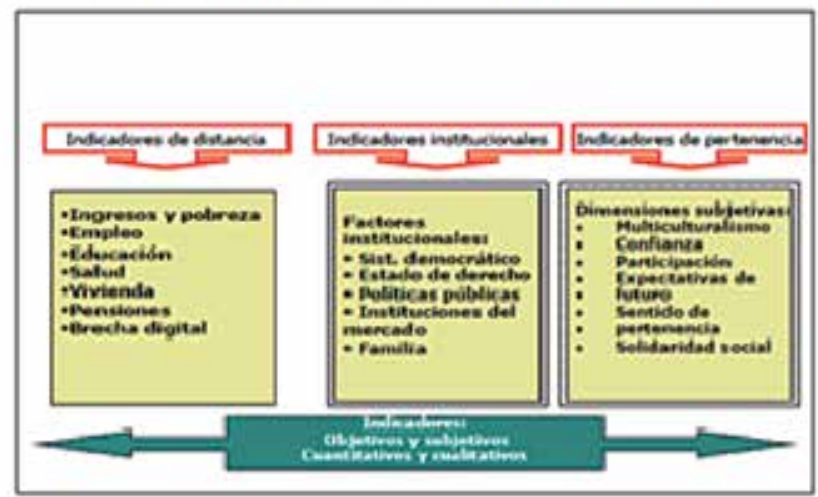

Faste. Elabersiba grepia 
Gráfica 12. Tasa de desempleo por grupos poblacionales en febrero

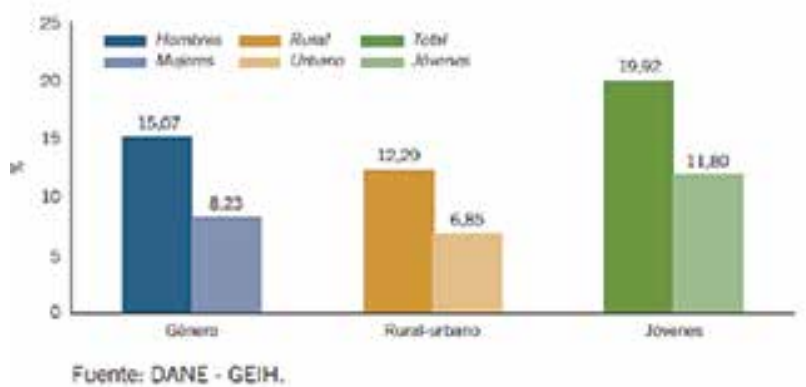

A febrero del año 2013, la tasa de desempleo de los jóvenes se ubicó cerca del 20\%, muy superior a la tasa de desempleo total que se situó en el $11.8 \%$. Análogamente la tasa de desempleo en las mujeres se situó en el $15.07 \%$ mientras la de los hombres se situó en el $8.23 \%$ mostrando la amplia brecha de desempleo entre géneros.

Gráfica 13. tasa de ocupación y desempleo

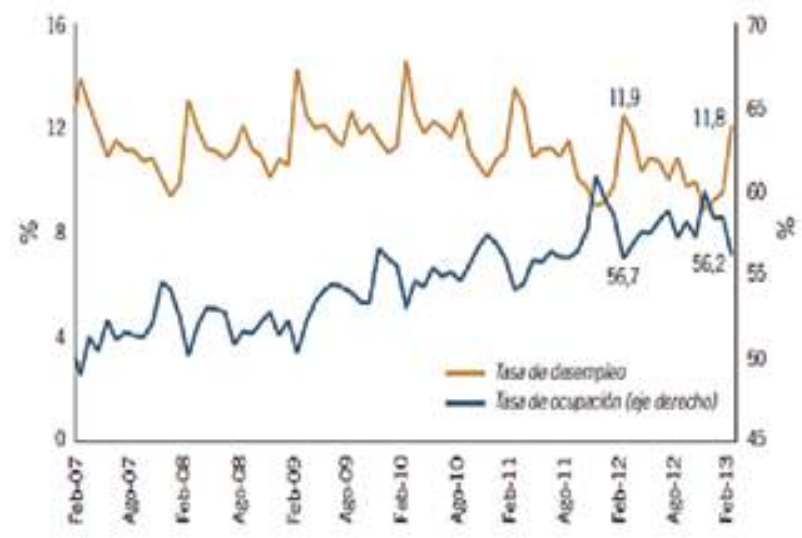

Gráfica 14. Recién graduados vinculados al sector forma

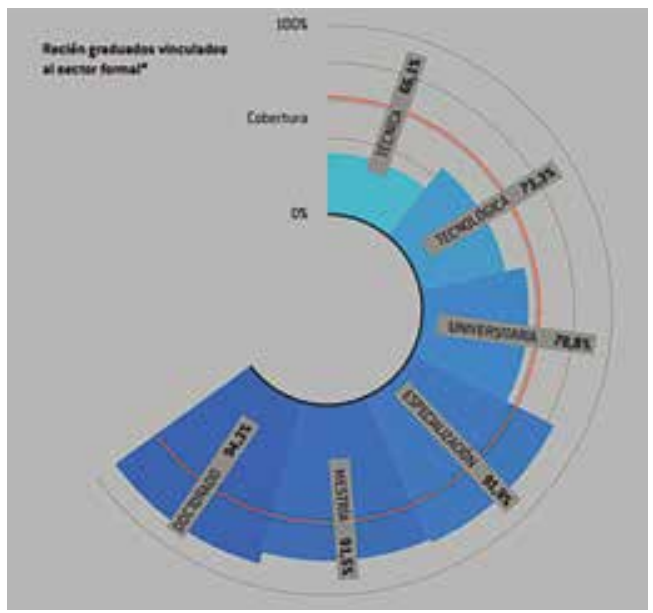

La tasa de desempleo en febrero del año 2013 se redujo con respecto a la del mismo mes del año 2012, situándose en el $11.8 \%$, sin embargo la tasa de ocupación también presento caída en el mismo periodo de tiempo ubicándose en el 56.2\%. Lo anterior teniendo en cuanta que la generación de empleo fue cercana a los 250 mil puestos de trabajo, principalmente en el comercio y hoteles, en contraste con los sectores de la construcción y la industria que destruyeron 268 puestos de trabajo. El grafico 14 muestra la participación en el mercado laboral formal, de los recién graduados en algún programa de educación superior; se destaca el alto porcentaje de los individuos con Doctorado (94.3\%) mientras el porcentaje de técnicos es del $66.1 \%$.

Gráfica 15. Desempleo jefes de hogar

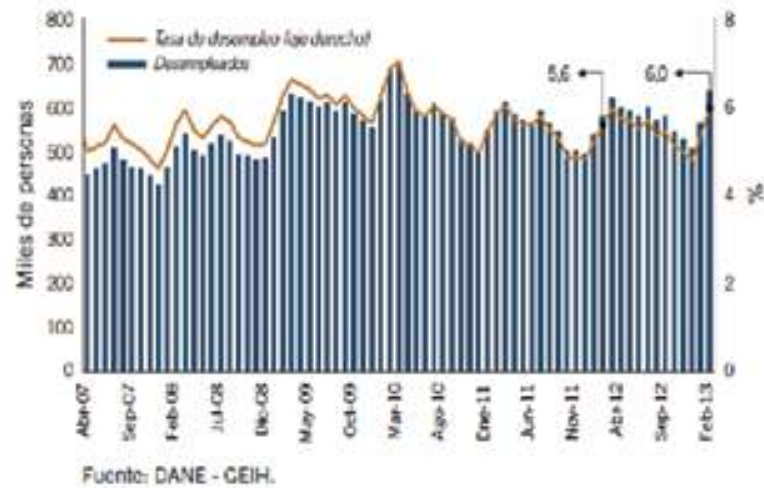

Gráfica 16. Generación de empleo por sectores económicos

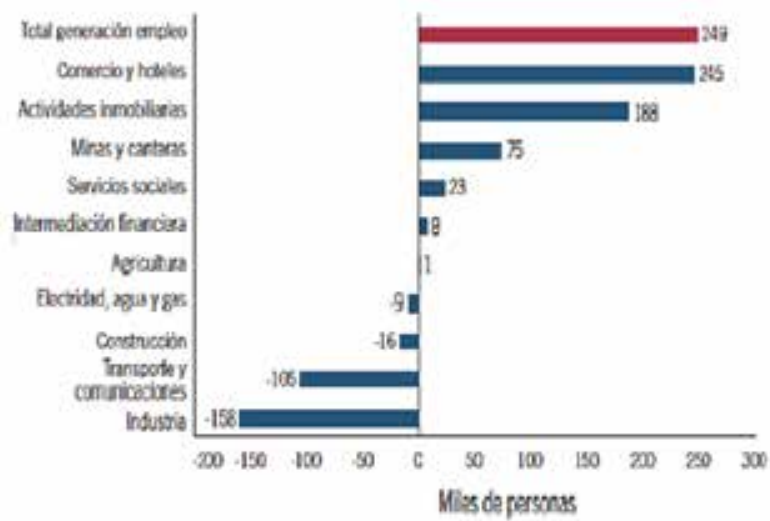

Fuente: DANE-GEH 
La tasa de desempleo de los jefes de hogar a febrero de 2013 presento aumento con respecto a febrero del año anterior, ubicándose en el 6\%. Lo cual justifica el aumento del número de desempleados jefes de hogar.

Gráfica 17 Informalidad, salario mínimo e ingresos por regiones

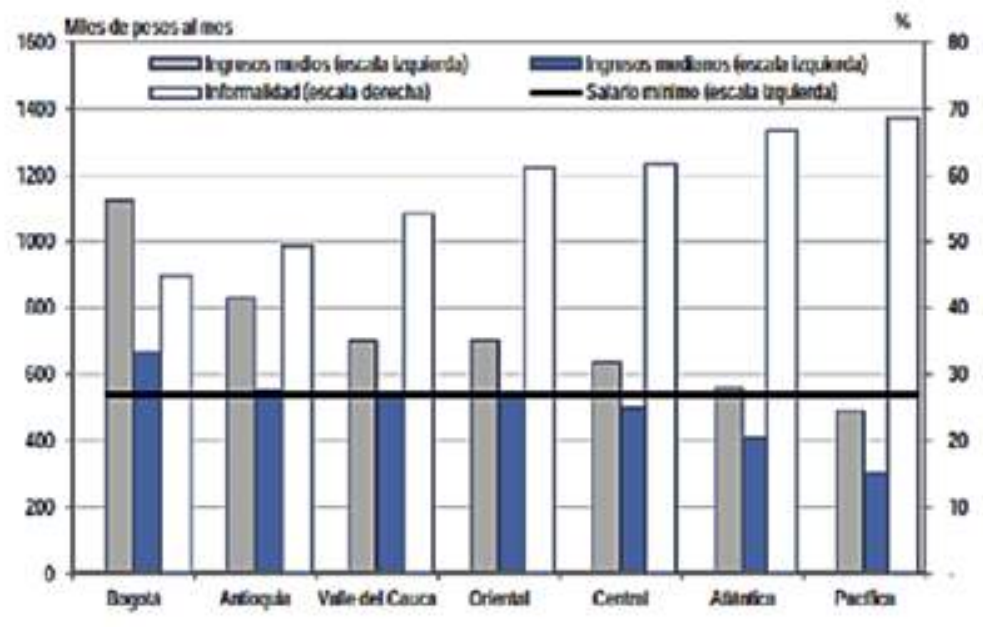

Fuente DANE - GEHH (Gran Encuesta Integrada de Hogares), 2011.

En la gráfica 17, el mayor nivel de informalidad en el año 2011 se registra en la zona Pacifica con casi el 70 por ciento, mientras en Bogotá el nivel de informalidad no alcanza el 50 por ciento, de la misma manera los mayores ingresos medios se registran en Bogotá con más de 600 mil pesos al mes, mientras en la zona pacifica no sobrepasan los 400 mil pesos.
La tasa de informalidad más alta se presenta en el grupo que presenta máximo de grado de educación primaria, seguido por los individuos con máximo grado de educación secundaria, mientras que las personas con educación superior presentan el $23.4 \%$ frente al total de los técnicos y profesionales. Los anteriores porcentajes solo incluyen a los individuos que cotizan al sistema de seguridad social, los que trabajan y no cotizan son incluidos en estas relaciones.

Gráfica 18. Gasto y rendimiento en educación e ingresos
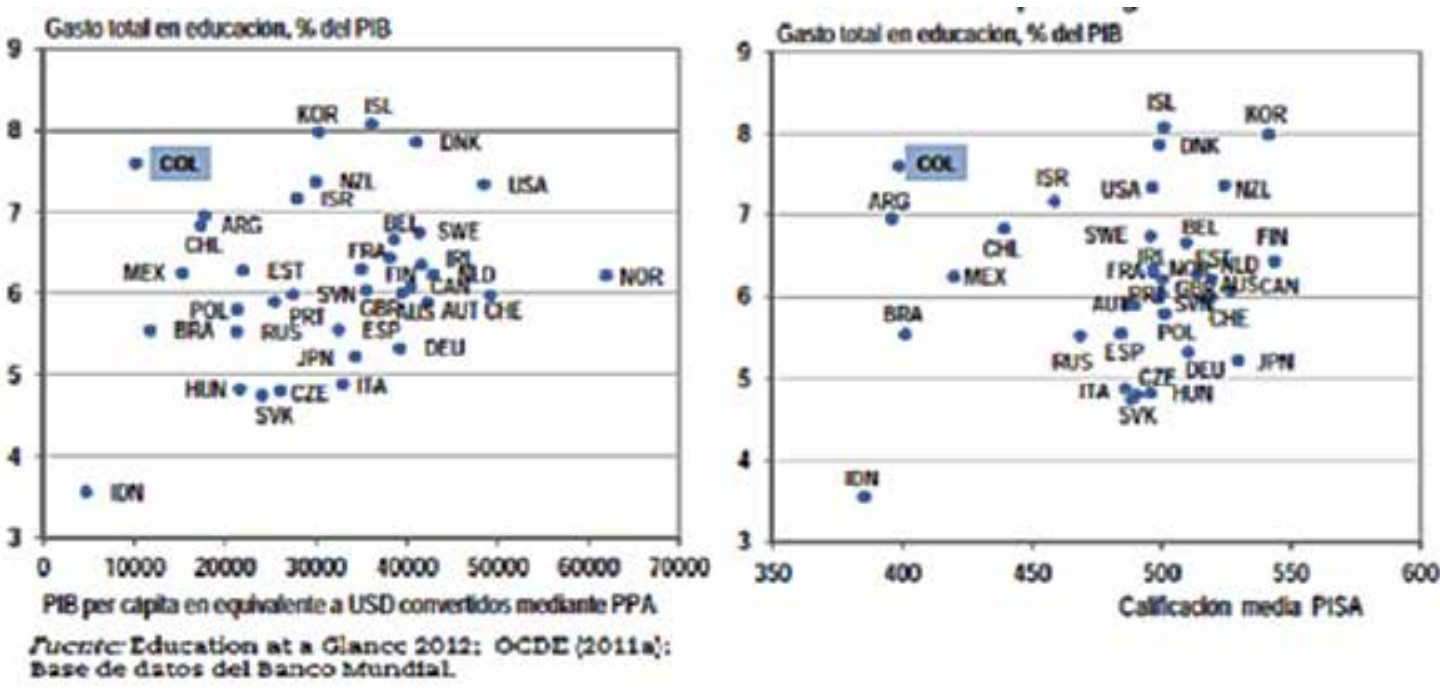


\section{Educación}

En el año 2012 la inversión en educación en Colombia se situó cerca al 8 por ciento del PIB, lo cual evidencia que al aumentar la función de ingresos aumenta el gasto, mientras el rendimiento en la educación no aumenta al mismo ritmo que el gasto. En el grafico 19, en el periodo 1990-2011 la productividad laboral en Colombia, medida como el valor del PIB por hora trabajada ha aumentado en el 20 por ciento mientras la productividad en América Latina y la OCDE han aumentado más del 40 por ciento. Se destaca la caída de la productividad en Colombia en el periodo 2000-2005.

Gráfica 19. Avance en la productividad laboral

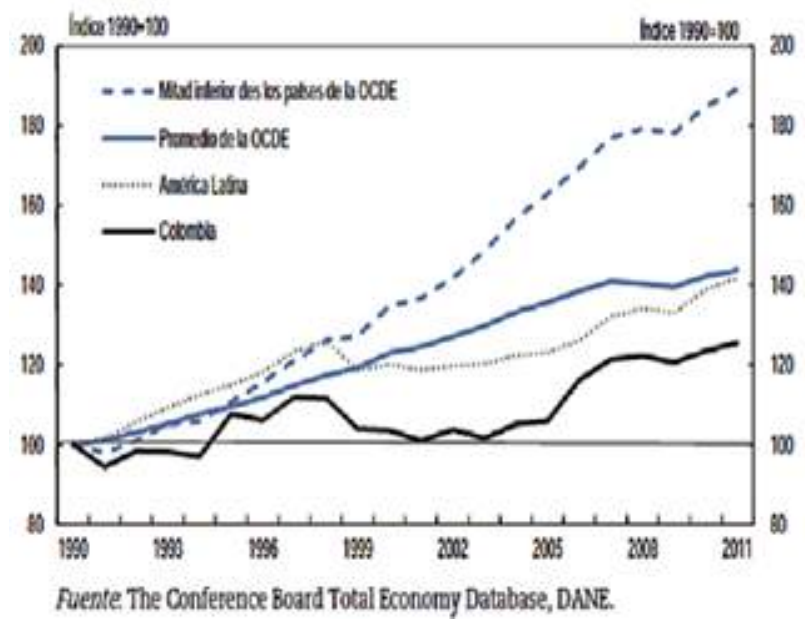

En el informe de la OCDE directrices de la 13a. Conferencia de estadisticos del trabajo de la oficina internacional del trabajo OIT para 2011 -12, Colombia ocupa el lugar 30, entre 36 países con elevada tasa de desempleo, lo que se refleja en la alta coincidencia con la Encuesta de hogares sobre el empleo, demostrado en una alta informalidad en la región oriental y central, costa atlántica y pacífica, especificándose ingresos medianos y salaros mínimos (17).

En el reporte de competitividad 2012 elaborado por el Institute for Management Development (IMD) Colombia continuo su caída en materia de competitividad, al pasar del puesto 46 en 2011 al puesto 52 en 2012, entre 59 países; lo mismo ocu- rrió con el Indicador Global de Competitividad del Word Economic Forum (WEF) con un retroceso del país de una posición 68 en 2011 a un 69 en 2012, entre 144 países, alejándose de la meta de los objetivos del milenio.

\section{Educación}

Según el informe de la OCDE- Banco Mundial Colombia 2012, el rendimiento en educación no aumenta a la par del gasto, lo cual se percibe en las bajas tasas de retorno de la educación y su consiguiente aporte al desarrollo. La capacitación del capital humano se destaca como una de las áreas estratégicas, desde la cual el país podría mejorar los niveles de competitividad en el marco de la gestión, uso de instrumentos financieros y la planificación de operaciones y negocios nacionales e internacionales, Una economía competitiva debe contar con capital humano altamente calificado. Colombia, ocupa el puesto 85 en el pilar de la educación primaria y secundaria y el puesto 67 en el de la educación superior (WEF.2012-2013), lo cual significa que no hay correspondencia entre el sistema educativo con la agenda de competitividad del país reflejado en la prueba PISA 2012 donde Colombia ocupo el puesto 62 de 65 países.

Colombia ha hecho avances importantes en cobertura, sin embargo persisten rezagos en algunos niveles, en particular en el área rural. En cobertura de educación superior, Colombia en promedio, presenta una cobertura del $37.2 \%$, la cual se considera significativamente baja y de una gran afectación en la lucha contra la informalidad en el país, de ahí que se recomienda incrementar la formación técnica y tecnológica, que presentan como característica una baja cobertura versus alta deserción del 45.3\%.

Frente a las situaciones observadas, el deber ser es pensar en una planeación estratégica para abordar la complejidad de los retos que genera esta situación, la cual debe plantearse desde una mirada integral que sea capaz de proponer acciones de tipo holístico y relacional, con el fin de dar respuesta a 
las problemáticas urbanas, políticas, sociales, económicas, medioambientales y culturales .

Las ciudades de América Latina y del Caribe tienen una problemática común, representada en migración, cambios climáticos, crisis económicas, problemas de desigualdad social, exclusión, pobreza y violencia que conducen a una completa descohesión social y a la vez son riesgo para la democracia y el desarrollo.

En consecuencia, la idea es lograr transformar las ciudades en centros generadores de cohesión social, convirtiéndolas en escenarios de realización personal, en el que cohabiten ciudadanos de todos los estratos sociales sin desmedro de ningún grupo en particular. Para lograr estas condiciones, se requiere la participación activa de todos los sectores: públicos, privados y comunitarios, direccionados por un gobierno activo y comprometido, que lidere y determine las mejores rutas de desarrollo para el avance y continuo bienestar de la población. Esto se logra en la medida en que la capacidad económica se vea fortalecida a través de reestructuración tecnológica y productiva, que se vea acompañada de la optimización de servicios básicos como son el saneamiento básico, la salud y la educación.

Es así, que la ciudad se debe repensar no solamente como un espacio físico sino como una comunidad de intereses comunitarios en lo económico, lo político y lo social, con participación ciudadana que comprometa a todos y todas en el cambio.

\section{Conclusiones}

La presencia de la pobreza agravada por el círculo vicioso de hambre desnutrición que ella engendra es inevitable; de ahí que esta situación continúa creciendo a pasos agigantados sin detenerse, debido en gran medida a la ausencia de una política pública cohesionadora de la sociedad.

Se requiere un desarrollo integral de las regiones traducido en oportunidades equilibradas a las mayorías a fin de encontrar las mejores rutas para el avance continuo del bienestar de la población y de la capacidad redistributiva de la economía, a través de procesos de restructuración tecnológica y productiva, del funcionamiento general de la sociedad y de la optimización de los servicios básicos.

Se propone que la titularidad de derechos humanos $y$ sociales, deje de considerarse sólo como un concepto político y se materialice en acciones concretas que incidan significativamente en la reducción de las brechas y desigualdades sociales que Representan una alta incidencia negativa en los indicadores de desarrollo humano de las comunidades.

La apuesta es por una sociedad cohesionada en torno a objetivos comunes de desarrollo social, económico y político, con una amplia participación de la comunidad en términos de empleo, educación, salud, en el marco de la protección social, participación ciudadana, sentido de pertenencia.

Una sociedad que no garantiza igualdad de oportunidades a toda la ciudadanía genera dinámicas de ruptura social, que erosionan e imposibilitan su cohesión e inciden en un ambiente de inseguridad e insatisfacción personal y colectiva que ilegitima las instituciones garantes de la política social plasmada en los planes de desarrollo.

Hay que luchar por encontrar la manera de implementar la cohesión social como parte del proyecto de vida de todos los seres humanos, reconstruyendo un sentido de pertenencia y de compromiso con la sociedad a través de objetivos sociales compartidos; minimizando las disparidades y evitando la polarización.

Es urgente como parte integral de la política pública nacional la construcción y puesta en marcha de un Plan Estratégico en el marco de la incorporación de la cohesión social para el aseguramiento del bienestar de todos los miembros de la sociedad (ciudadanos y ciudadanas) comprometidos con el cambio y la reestructuración social. 